\title{
MicroRNA-1236-3p/translationally controlled tumor protein (TPT1) axis participates in congenital hypothyroidism progression by regulating neuronal apoptosis
}

\author{
TINGTING MENG* ${ }^{*}$ SHIMAN SHEN* ${ }^{*}$ CHENG LI and XUEHUA LIU \\ Pediatric Blood Care Station, The First Hospital of Jilin University, Changchun, Jilin 130012, P.R. China
}

Received November 18, 2018; Accepted August 12, 2019

DOI: $10.3892 /$ etm.2019.8262

\begin{abstract}
Congenital hypothyroidism $(\mathrm{CH})$ is an endocrine disease caused by congenital thyroid hormone (TH) deficiency. MicroRNAs (miRNAs or miRs) have been reported to inhibit the progression of congenital hypothyroidism. However, the expression and role of miR-1236-3p in $\mathrm{CH}$ remains unclear. To address this, 12 day old Sprague-Dawley rats were divided into five groups: Control; Congenital hypothyroidism $(\mathrm{CH})$, miR-1236-3p inhibitor control (inhibitor control); miR-1236-3p inhibitor (inhibitor); and miR-1236-3p inhibitor + translationally-controlled tumor protein 1 (TPT1)-small interfering (si)RNA (inhibitor + siRNA). Propylthiouracil (50 mg/day) was injected intraperitoneally into pregnant rats to generate pups with $\mathrm{CH}$. The levels of miR-1236-3p and TPT1 were detected via reverse transcription-quantitative PCR and western blot analysis. Bioinformatics analysis was performed to predict the targets of miR-1236-3p, which was confirmed using dual luciferase reporter assay. Flow cytometry and MTT assay were used to measure neuronal cell apoptosis and cell viability, whereas western blotting was applied to detect the expression of Pim-3, p-Bad (Ser112), Bad and Bcl-xL, proteins associated with apoptosis. The results revealed that miR-1236-3p expression was significantly upregulated, whilst TPT1 expression was significantly downregulated in the hippocampus tissues of $\mathrm{CH}$ rats compared with the control group. TPT1 was confirmed as a target of miR-1236-3p. MiR-1236-3p inhibitor prevented hippocampal neuron apoptosis induced by $\mathrm{CH}$ induction, which was reversed by TPT1-siRNA transfection. In addition, following miR-1236-3p inhibitor transfection, neuronal cell
\end{abstract}

Correspondence to: Dr Xuehua Liu, Pediatric Blood Care Station, The First Hospital of Jilin University, 71 Xinmin Street, Changchun, Jilin 130012, P.R. China

E-mail: liuxh201718@163.com

*Contributed equally

Key words: congenital hypothyroidism, microRNA-1236-3p, translationally-controlled tumor protein 1, hippocampal, neuronal, cell apoptosis apoptosis significantly reduced compared with the control group, which was accompanied by significantly increased expressions of Pim-3, p-Bad (Ser112) and Bcl-xL expression. These effects were reversed by TPT1-siRNA co-transfection. These results indicated that inhibition of miR-1236-3p expression inhibited neuron apoptosis in vivo and in vitro by targeting TPT1, serving a protective role in $\mathrm{CH}$.

\section{Introduction}

Congenital hypothyroidism $(\mathrm{CH})$ is a form of general endocrine disease caused by congenital thyroid hormone (TH) deficiency (1). The incidence of $\mathrm{CH}$ in newborn infants ranges between 1/3,000 and 1/4,000 (2). This condition is treatable if diagnosed early, but later diagnoses can lead to physical and mental abnormalities (3). Therefore, the accurate timing of thyroid hormone replacement therapy in humans is critical for optimizing neurocognitive recovery. $\mathrm{CH}$ results in cognitive deficiency (4), motor deficits (5) and behaviors associated with anxiety (6). Timely and effective screening of newborns would enable early diagnosis and treatment, with the aim of improving the prognosis of children. In addition, quality care can improve the completion rate of $\mathrm{CH}$ screening in newborns more effectively. Therefore, early detection, diagnosis, scientific and effective nursing and treatment are crucial for improving the prognosis of children with congenital hypothyroidism and improving the quality of the population.

$\mathrm{TH}$ is essential for the proper development of the mammalian brain. TH deficiency results in serious structural and functional damage to the central nervous system (7). In particular, $\mathrm{CH}$ leads to neutrophil damage, abnormal cerebellar growth and differentiation (8-10). The hippocampus is an important center responsible for cognitive activities in humans. Indeed, children with $\mathrm{CH}$ who experience neonatal thyroid hormone deficiency exhibit reduced hippocampal volumes compared with healthy controls (11). A previous study has reported that perinatal hypothyroidism may induce apoptosis in hippocampal neurons in rats (12). Following early diagnosis of $\mathrm{CH}$, neurodevelopmental dysplasia could still occur if treatment is not optimized within the first 2-3 years of birth (13). Therefore, patients with $\mathrm{CH}$ must undergo early treatment followed by close follow-up.

MicroRNAs (miRNAs) are non-coding single stranded small RNAs consisting of 18-25 nucleotides that do not encode 
proteins (14). Mature miRNA directly bind to mRNAs to regulate their expression (15). Recent research has suggested that miRNAs participate widely in diseases involving the nervous system, including congenital hypothyroidism (16). For example, a previous study has demonstrated that miR-124 inhibits the progression of congenital hypothyroidism (16). Previous studies have revealed that miR-1236 can serve different roles in a tissue- or physiological-dependent manners. miR-1236 attenuates human lymphatic endothelial cell migration and tube formation (in vitro angiogenesis detection) in addition to angiogenesis in the lymphatic system in vivo (17). In contrast, miR-1236-3p has been found to repress ovarian cancer metastasis (18). However, the role of miR-1236-3p in congenital hypothyroidism remains unclear.

Translationally-controlled tumor protein 1 (TPT1) is a highly conserved protein that has been reported to be strongly expressed in a variety of malignant tumors, where it regulates cell proliferation, invasion, cell cycle and apoptosis (19-21). Indeed, TPT1 downregulation has been demonstrated to inhibit cell proliferation and induce cell cycle arrest and apoptosis in pancreatic cancer (22). Furthermore, miR-489-3p has been revealed to inhibit glioblastoma progression by acting through the downregulation of TPT1 (23).

The present study aimed to clarify the role of miR-1236-3p in $\mathrm{CH}$ by investigating the function of this miRNA in hippocampal neuron apoptosis in vivo and in vitro using a rat model.

\section{Materials and methods}

Reagents. Propylthiouracil was obtained from Beyotime Institute of Biotechnology. This protocol followed and dosage of Propylthiouracil used was performed/selected according to a previous study (24). The miR-1236-3p inhibitor and its corresponding negative control (inhibitor control), TPT1-siRNA (cat no. XWCRR2962; Zhejiang Huijia Biotechnology Co., Ltd.) and control-siRNA (cat no. 9500C-1; Zhejiang Huijia Biotechnology Co., Ltd.) were purchased from Shanghai GenePharma Co., Ltd.

Experimental animals. A total of 50 female pregnant

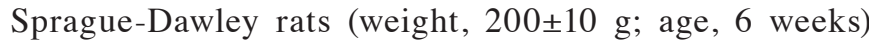
obtained from Vital River Laboratories Co., Ltd. were used. All rats were maintained at room temperature with a humidity of 55\% and ad libitum access to standard pellet feed and water under a 12-h light/dark cycle. Propylthiouracil (50 mg/day) was injected intraperitoneally into pregnant rats on day 15 of gestation and then carried out every day thereafter until parturition to generate pups with congenital hypothyroidism (24). For the treatment of $\mathrm{CH}$ pups, animals were anesthetized with an intraperitoneal injection of $2 \%$ sodium pentobarbital (40 mg/kg). Newborn rats (12 days old) were subsequently fixed on a stereotaxic apparatus and their skulls were opened at $1.0 \mathrm{~mm}$ from the former fontanel and $1.7 \mathrm{~mm}$ from the mid-line (16). A micro syringe was then inserted vertically into the left lateral ventricle (bregma: $-0.58 \mathrm{~mm}$; dorsoventral: $2.1 \mathrm{~mm}$; lateral: $1.2 \mathrm{~mm}$ ) and pups were injected with miR-1236-3p inhibitor control solution (5 $\mu \mathrm{l} ; 1 \mathrm{nmol} / \mathrm{l})$, miR-1236-3p inhibitor (5 $\mu \mathrm{l}$; $1 \mathrm{nmol} / \mathrm{l})$ or miR-1236-3p inhibitor $(5 \mu \mathrm{l} ; 1 \mathrm{nmol} / \mathrm{l})+$ TPT1-siRNA solution $(5 \mu \mathrm{l} ; 1 \mathrm{nmol} / \mathrm{l})$ as previously described (25). The newborn rats (12 days old in all groups) were divided into five groups $(n=5)$ : Control group (newborn rats from pregnant rat that was received food and normal tap water ad libitum without propylthiouracil treatment); congenital hypothyroidism $(\mathrm{CH})$ group [newborn pups from pregnant rats that were injected intraperitoneally with Propylthiouracil $(50 \mathrm{mg} / \mathrm{d})$ on day 15 of gestation each day until parturition]; miR-1236-3p inhibitor control group [12 day old $\mathrm{CH}$ newborn rats injected miR-1236-3p inhibitor control as previously described (25)]; miR-1236-3p inhibitor group [12 day old $\mathrm{CH}$ newborn rats were injected with miR-1236-3p inhibitor as previously described (25)]; and miR-1236-3p inhibitor + TPT1-siRNA group [12 day old CH newborn rats were injected with miR-1236-3p inhibitor + TPT1-siRNA as previously described (25)].

This animal experiment lasted for 36 days in total, and the health and behaviors (including diet, drinking, tail swing, sucrose preference, swimming) of all rats were monitored every 2 days. No rats died for the duration the aforementioned experimental procedures. The experiments were ended when the rats lost $>15 \%$ of their body weight (body weight prior to injection). On day 21 after birth, newborn rats (21 day old; body weight $<200 \mathrm{~g}$ ) were anesthetized with pentobarbital (40 mg/kg) by intraperitoneal injection and sacrificed by cervical dislocation (death defined as the lack of heartbeat and breathing). The brain hippocampus tissue was subsequently harvested following euthanasia. The mother rats $(24 \mathrm{~h}$ after the pups were born) from which the pups were obtained were also anesthetized with pentobarbital $(40 \mathrm{mg} / \mathrm{kg})$ and then sacrificed by cervical dislocation, with death defined as the lack of heartbeat and breathing. The experimental procedure of the present study regarding the establishment of the $\mathrm{CH}$ rat model and treatment process is presented in Fig. S1. All animal care and experimental procedures were performed in accordance with the National Institutes of Health Guide for Care and approved by the Animal Ethics Committee of the First Hospital of Jilin University.

Cell culture and transfection. Hippocampal neurons were prepared from the hippocampus of postnatal day 0 rat pups from the control group, as previously described (26). Neurons were cultured using Dulbecco's modified Eagle's medium (Gibco; Thermo Fisher Scientific, Inc.) containing 10\% fetal bovine serum (Gibco; Thermo Fisher Scientific, Inc.) in poly-D lysine-coated plates at a density of $1 \times 10^{6}$ cells $/ \mathrm{ml}$. After culturing for $6 \mathrm{~h}$ at $37^{\circ} \mathrm{C}$ and $5 \% \mathrm{CO}_{2}$, the cell culture medium was replaced with neurobasal medium (Gibco; Thermo Fisher Scientific, Inc.) containing 2\% B27 (cat. no. 17504-044; Life Technologies; Thermo Fisher Scientific, Inc.), $100 \mathrm{U} / \mathrm{ml}$ penicillin, $100 \mathrm{~g} / \mathrm{ml}$ streptomycin and $0.5 \mathrm{mM}$ glutamine (Gibco; Thermo Fisher Scientific, Inc.) and then incubated at $37^{\circ} \mathrm{C}$ in a humidified atmosphere under $5 \% \mathrm{CO}_{2}$. The culture medium was replaced once every 3 days.

Neurons were seeded into 6-well plates $\left(5 \times 10^{4}\right.$ cells/well $)$ and transfected with miR-1236-3p inhibitor, miR-1236-3p inhibitor control (inhibitor control), TPT1-siRNA, control-siRNA, miR-1236-3p inhibitor + control-siRNA or miR-1236-3p inhibitor + TPT1-siRNA using Lipofectamine ${ }^{\circledR} 2000$ (Thermo Fisher Scientific, Inc.) according to manufacturer's protocol. Neurons were collected for subsequent experiments after $48 \mathrm{~h}$ of transfection. 
MTT assay. Cell viability of neurons was measured via an MTT assay. Cells were first cultured in 96-well plates $\left(1 \times 10^{4}\right.$ cells/well) at $37^{\circ} \mathrm{C}$ for $24 \mathrm{~h}$ and then transfected with the miR-1236-3p inhibitor, inhibitor control, miR-1236-3p inhibitor + control-siRNA or miR-1236-3p inhibitor + TPT1-siRNA for $48 \mathrm{~h}$, as aforementioned. Following incubation, $10 \mu \mathrm{l} \mathrm{MTT}$ solution was added into each well and incubated for a further $4 \mathrm{~h}$ at $37^{\circ} \mathrm{C}$ under $5 \% \mathrm{CO}_{2}$. A total of $150 \mu \mathrm{l}$ dimethyl sulfoxide (DMSO) was used to dissolve the formazan crystals. Optical density at $490 \mathrm{~nm}$ was measured in each well using a microplate reader.

Flow cytometry. A BD FACSCalibur ${ }^{\mathrm{TM}}$ Flow cytometer (BD Biosciences) was used to analyze neuronal cell apoptosis. Neurons $\left(1 \times 10^{5}\right.$ cells/well) were first digested using $0.25 \%$ trypsin, washed with PBS and fixed in $70 \%$ ice-cold ethanol overnight at $4^{\circ} \mathrm{C}$. The neurons were subsequently added with $5 \mu \mathrm{l}$ fluorescein isothiocyanate-labeled Annexin $\mathrm{V}$ and $5 \mu \mathrm{l}$ propidium iodide (PI; cat. no. 6592; Cell Signaling Technology, Inc.). Then, the neurons were incubated at $4^{\circ} \mathrm{C}$ for $30 \mathrm{~min}$ in the dark. Cell apoptosis was analyzed and calculated (right quadrants) using FlowJo software (version 7.6.1; Tree Star Inc.).

Reverse transcription-quantitative polymerase chain reaction (RT-qPCR). Total RNA was extracted from the hippocampus tissues and hippocampus neurons using TRIzol reagent (Invitrogen; Thermo Fisher Scientific, Inc.) according to manufacturer's protocol. RNA was reverse transcribed into cDNA using the PrimeScript ${ }^{\mathrm{TM}}$ RT reagent kit (Takara Biotechnology Co., Ltd.) according to manufacturer's protocol. qPCR was performed using Maxima ${ }^{\mathrm{TM}}$ SYBR Green qPCR Master Mix (2x) (Fermentas; Thermo Fisher Scientific, Inc.) according to manufacturers' protocols. The primer sequences used for qPCR were as follows: TPT1 forward, 5'-ATGATTATCTACCGG GACCTC-3' and reverse, 5'-TACATTTTTCCATTTCTAAAC CATCC-3'; GAPDH forward, 5'-CTTTGGTATCGTGGA AGGACTC-3' and reverse, 5'-GTAGAGGCAGGGATGATG TTCT-3'; U6 forward, 5'-CTCGCTTCGGCAGCACATATA CT-3' and reverse, 5'-ACGCTTCACGAATTTGCGTGTC-3'; miR-1236-3p forward, 5'-CCAATCAGCCTCT-TCCCCTT-3 and reverse, 5'-TATGGTTGTTCACGACTCCT-TCAC-3'. The thermocycling conditions were as follows: $5 \mathrm{~min}$ at $95^{\circ} \mathrm{C}$ and 40 cycles of $30 \mathrm{sec}$ at $95^{\circ} \mathrm{C}, 30 \mathrm{sec}$ at $60^{\circ} \mathrm{C}$ and $30 \mathrm{sec}$ at $72^{\circ} \mathrm{C}$. U6 for (miRNA) and GAPDH (for mRNA) were used as the internal control. Quantification was performed using the $2^{-\Delta \Delta \mathrm{Cq}}$ method (27).

Western blot analysis. After cell transfection, the neuronal cells were homogenized in cell lysis buffer (10x; Cell Signaling Technology, Inc.) containing protease inhibitors. Proteins were quantified using Bicinchoninic Acid Assay kit (Thermo Fisher Scientific, Inc.) and subsequently separated (30 $\mu \mathrm{g} /$ lane) via $12 \%$ SDS-PAGE prior to transferal onto PVDF membranes. The membranes were blocked with 5\% skim milk in TBS containing $0.1 \%$ Tween at room temperature for $2 \mathrm{~h}$, and then incubated with primary antibodies against TPT1 (cat. no. 5128; 1:1,000; Cell Signaling Technology, Inc.), Serine/Threonine Kinase Pim-3 (Pim-3; cat. no. 4165; 1:1,000; Cell Signaling Technology, Inc.),

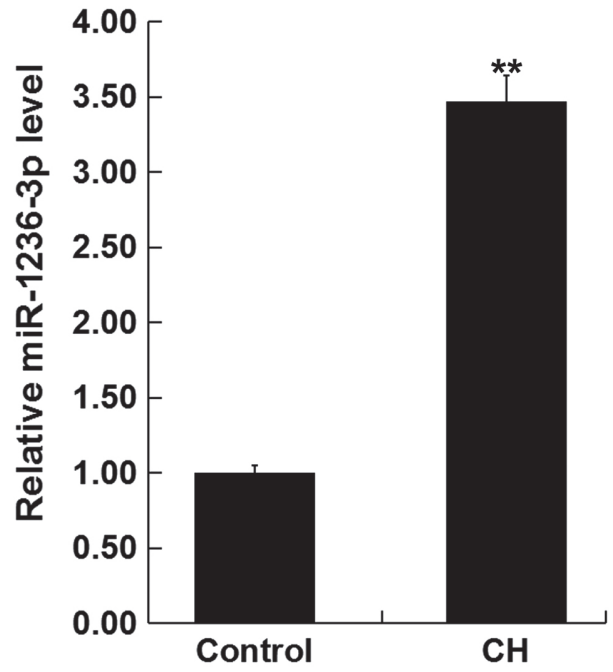

Figure 1. Level of miR-1236-3p in the hippocampus of newborn rats with $\mathrm{CH}$. RT-qPCR was used to measured the level of miR-1236-3p in the hippocampus of newborn rats with or without $\mathrm{CH} .{ }^{* *} \mathrm{P}<0.01$ vs. Control. miR, microRNA; $\mathrm{CH}$, congenital hypothyroidism.

phosphorylated (p)-Bad (Ser112) (cat. no. 5284; 1:1,000; Cell Signaling Technology, Inc.), Bad (cat. no. 9268; 1:1,000; Cell Signaling Technology, Inc.), Bcl-xL (cat. no. 2764; 1:1,000; Cell Signaling Technology, Inc.) and $\beta$-actin (cat. no. 4970; 1:1,000; Cell Signaling Technology, Inc.) at $4^{\circ} \mathrm{C}$ overnight. Subsequently, the membranes were then incubated with Anti-rabbit IgG, HRP-linked Antibody (cat. no. 7074; 1:2,000; Cell Signaling Technology, Inc.) at room temperature for $1 \mathrm{~h}$. Protein bands were visualized using enhanced chemiluminescence (Cell Signaling Technology, Inc.). Densitometry analysis was performed using Gel-Pro Analyzer densitometry software (Version 6.3; Media Cybernetics, Inc.).

Dual luciferase reporter assay. Bioinformatics software 7.1 (http://www.targetscan.org/vert_71/) was used to predict potential targets of miR-1236-3p. The binding sites between the 3'-untranslated region (3'-UTR) of TPT1 and miR-1236-3p were observed. A dual luciferase reporter assay was used to investigate whether miR-1236-3p directly targets the 3'-UTR of TPT1. The wild-type (WT) 3'UTR of TPT1 or the mutant (MUT) 3'UTR TPT1 were cloned into the dual-luciferase reporter vector pmiR-RB-REPORT (Guangzhou RiboBio Co., Ltd.) following the manufacturer's instructions. Hippocampal neurons were subsequently prepared from the hippocampus of postnatal day 0 rat pups in the control group $\left(5 \times 10^{4}\right.$ cells per well) were first seeded into 24 -well plates and co-transfected with either TPT1-3'-UTR-wild type (WT) or TPT1-3'-UTR-mutant (MUT) plasmids and miR-1236-3p mimics (forward 5'-CGCGGATCCCTGGCCCTCACTTAC CTC-3' and reverse 5'-CCGAATTCCCATCTACATTCC AACTTGGAG-3' or mimic control (forward, 5'-UUCUCC GAACGUGUCACGUTT-3' and reverse, 5'-ACGUGACAC GUUCGGAGAATT-3') using Lipofectamine ${ }^{\circledR} 2000$ (Thermo Fisher Scientific, Inc.). After 48 h, the relative luciferase activities were measured using a dual luciferase reporter assay kit (Promega Corporation) according to manufacturer's protocol. All luciferase activities were normalized to Renilla luciferase activity. 

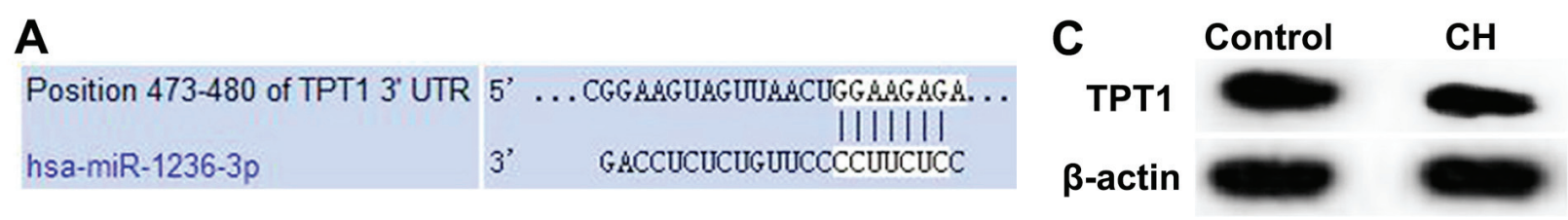

B

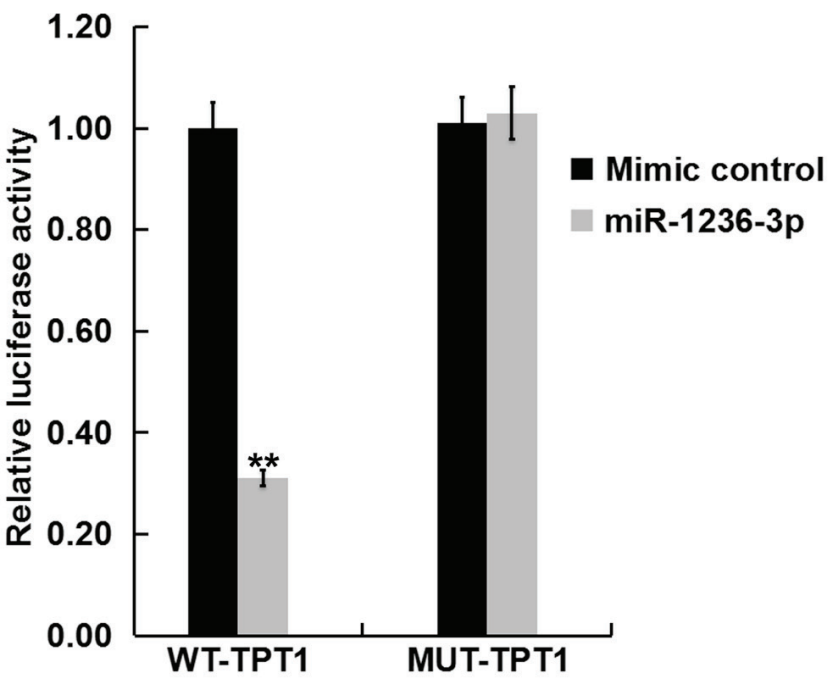

D 1.20

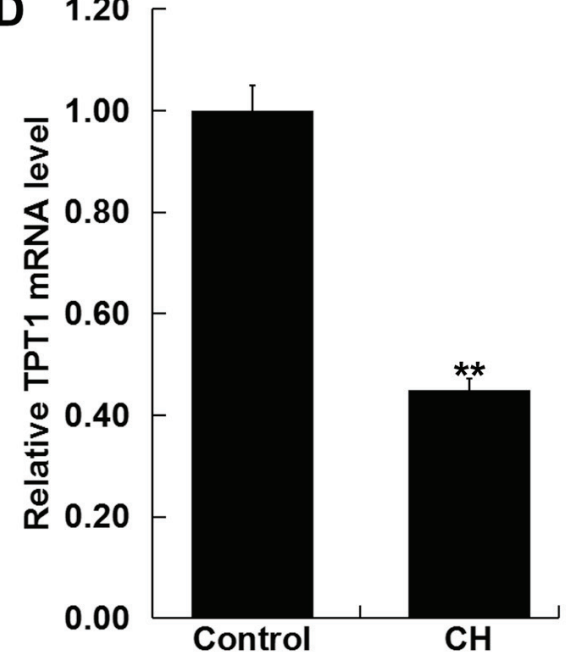

Figure 2. Association between miR-1236-3p and TPT1. (A) TargetScan software predicted a miR-1236-3p binding site in the 3'-UTR of TPT1. (B) A Dual-luciferase reporter assay was performed to validate the potential association between miR-1236-3p and TPT1 as proposed in (A), in neuronal cells co-transfected with either miR-1236-3p mimic or mimic control and WT TPT1 or MUT-TPT1. * P<0.01 vs. WT-TPT1 mimic control. (C) Western blot analysis of TPT1 protein expression. (D) Reverse transcription-quantitative PCR analysis of TPT1 mRNA expression. Data were presented as the mean \pm standard deviation. ${ }^{* *} \mathrm{P}<0.01$ vs. Control. 3'-UTR, 3'-untranslated region; miR, microRNA; TPT1, translationally-controlled tumor protein 1; UTR, untranslated region; WT, wild-type; MUT, mutant-type.

Statistical analysis. All experiments were repeated three times. Data were presented as the mean \pm standard deviation. The significance of differences between groups was evaluated using Student's t-test or analyzed via one-way ANOVA followed by a Tukey's post hoc test. $\mathrm{P}<0.05$ was considered to indicate a statistically significant difference.

\section{Results}

MiR-1236-3p is upregulated in rats with $\mathrm{CH}$. Changes in $\mathrm{miR}-1236-3 \mathrm{p}$ expression in the hippocampus tissue of newborn pups after the establishment of $\mathrm{CH}$ were first measured using RT-qPCR. Compared with the newborn pups of the control group, the expression of miR-1236-3p was significantly higher in the hippocampus tissue of newborn pups with $\mathrm{CH}$ (Fig. 1).

TPT1 is a target of $m i R-1236-3 p$. TargetScan revealed a potential miR-1236-3p binding site on the 3'-UTR of TPT1 (Fig. 2A). Dual-luciferase reporter assay results demonstrated that transfection with miR-1236-3p mimic significantly reduced luciferase activity in neurons that were also co-transfected with TPT1-WT group but not in those co-transfected with TPT1-MUT (Fig. 2B). This observation indicated that TPT1 is a direct target of miR-1236-3p. To support this, levels of TPT1 expression in the hippocampus tissue of newborn pups with or without $\mathrm{CH}$ was determined via RT-qPCR and western blotting. Compared with the control group, TPT1 protein (Fig. 2C) expression markedly reduced in the hippocampus tissues of rats with $\mathrm{CH}$. Compared with the control group, TPT1
mRNA (Fig. 2D) expression was significantly reduced in the hippocampus tissues of rats with $\mathrm{CH}$.

Inhibition of miR-1236-3p mitigates $\mathrm{CH}$ newborn pups hippocampal neuronal cell apoptosis in vivo. The effects of miR-1236-3p on neuronal cell apoptosis in rats with $\mathrm{CH}$ was assessed via flow cytometry. Compared with the control group, neuronal cells isolated from rats in the $\mathrm{CH}$ group exhibited significantly increased cell apoptosis (Fig. 3A and B). Injection with miR-1236-3p inhibitor significantly reduced $\mathrm{CH}$-induced neuronal cell apoptosis, an effect that was reversed by co-injection with TPT1-siRNA (Fig. 3A and B). Overall, these results indicated that inhibition of miR-1236-3p prevented neuronal cell apoptosis in rats with $\mathrm{CH}$.

Inhibition of miR-1236-3p protects cultured neurons from apoptosis in vitro. Neuronal cells were isolated from the hippocampus of postnatal day 0 rat pups from the control group and subsequently transfected with either miR-1236-3p inhibitor, inhibitor control or miR-1236-3p inhibitor + TPT1-siRNA. Transfection efficiency was first assessed via RT-qPCR. Transfection with the miR-1236-3p inhibitor significantly reduced the levels of miR-1236-3p in neurons (Fig. 4A), whilst TPT1-siRNA transfection significantly reduced TPT1 mRNA level in cultured neurons (Fig. 4B). TPT1-siRNA transfection also markedly reduced TPT1 protein level in cultured neurons (Fig. 4C). Compared with the inhibitor control group, transfection with the miR-1236-3p inhibitor significantly increased TPT1 mRNA expression, which was reversed by 
A

$\mathrm{CH}$
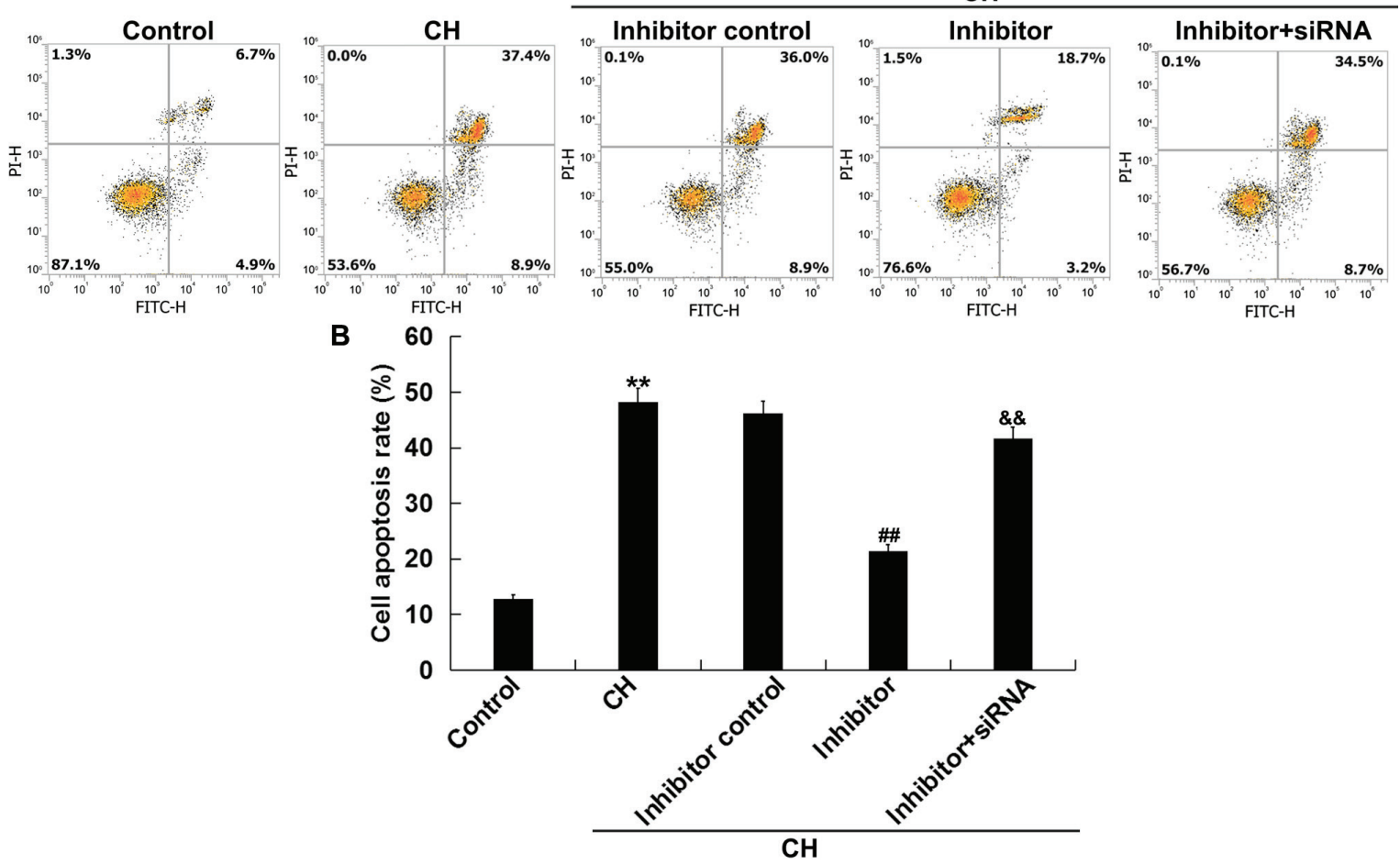

Figure 3. Effect of miR-1236-3p inhibition and/or TPT1 knockdown on CH newborn pups hippocampal neuronal cell apoptosis in vivo, using Annexin V FITC/PI assay. Flow cytometry was used to measure apoptosis of neurons in newborn rats from their respective treatment groups. (A) representative dot plots of flow cytometry; (B) quantified data of cell apoptosis. " $\mathrm{P}<0.01$ vs. Control; ${ }^{* \#} \mathrm{P}<0.01$ vs. inhibitor control; \& $\mathrm{P}<0.01$ vs. Inhibitor. miR, miRNA; TPT1, translationally-controlled tumor protein $1 ; \mathrm{CH}$, congenital hypothyroidism; PI, propidium iodide.
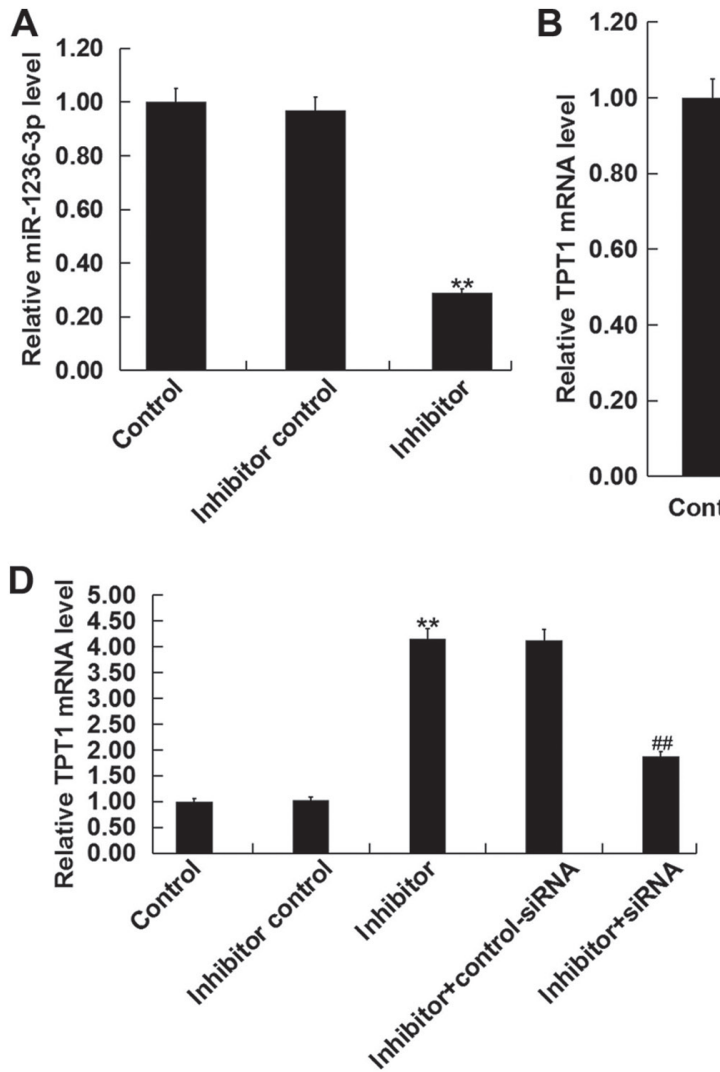

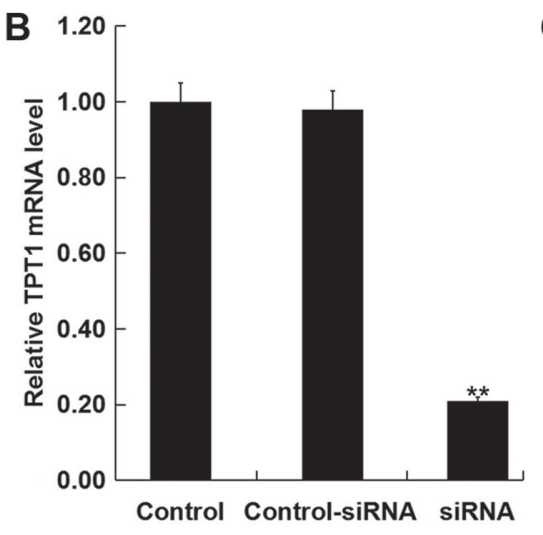

E

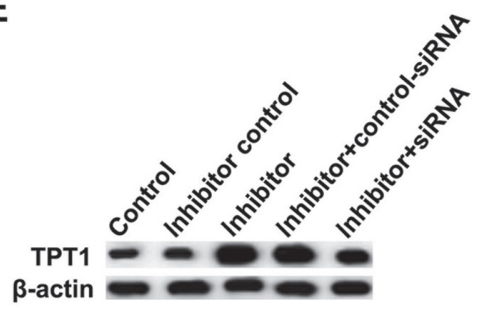

Figure 4. miR-1236-3p negatively regulates TPT1 expression in cultured neurons. (A) The levels of miR-1236-3p expression in cultured neurons transfected with either miR-1236-3p inhibitor or inhibitor control. (B) TPT1 mRNA and (C) protein expression in cultured neurons transfected with either TPT1-siRNA or control-siRNA. (D) TPT1 mRNA and (E) protein expression in cultured neurons co-transfected with either miR-1236-3p inhibitor or inhibitor control and control-siRNA or TPT1-siRNA. ${ }^{* *} \mathrm{P}<0.01$ vs. inhibitor control; ${ }^{\# /} \mathrm{P}<0.01$ vs. Inhibitor + control-siRNA. miR, microRNA; TPT1, translationally-controlled tumor protein 1; siRNA, small interfering RNA. 

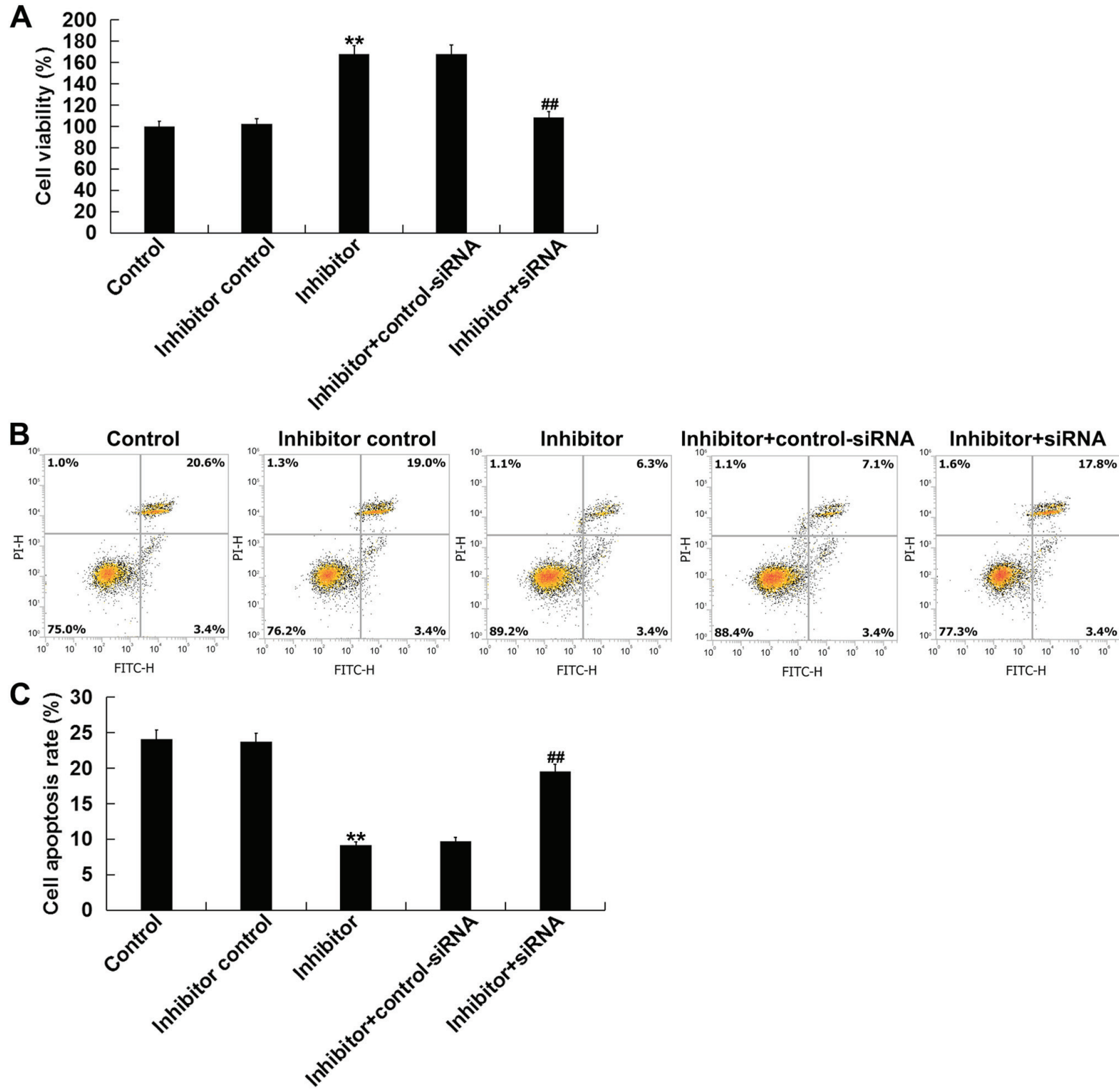

Figure 5. Effect of miR-1236-3p inhibitor and/or TPT1 knockdown on cell viability and apoptosis of cultured neurons in vitro. (A) Cultured neuronal cell viability was determined after $48 \mathrm{~h}$ using MTT assay. (B and C) Flow cytometry was used to analyze cultured neuronal cell apoptosis. (B) Representative dot plots in cultured neuronal cells co-transfected with either miR-1236-3p inhibitor or inhibitor control and TPT1-siRNA or control siRNA. (C) Quantified results of (B). ${ }^{* *} \mathrm{P}<0.01$ vs. inhibitor control; ${ }^{\# \#} \mathrm{P}<0.01 \mathrm{vs}$. Inhibitor + control-siRNA. miR, microRNA; TPT1, translationally-controlled tumor protein 1 ; siRNA, small interfering RNA; PI, propidium iodide; FITC, fluorescein isothiocyanate.

co-transfection with TPT1-siRNA (Fig. 4D). Similar results were observed from western blot assay (Fig. 4E).

Next, the effects of miR-1236-3p on cultured neuronal cell apoptosis in vitro was assesed. Compared with the inhibitor control group, transfection with the miR-1236-3p inhibitor significantly increased the neuronal cell viability after $48 \mathrm{~h}$ (Fig. 5A) whilst inhibiting neuronal cell apoptosis (Fig. 5B and C), effects that were significantly reversed by co-transfection with TPTI-siRNA.

Inhibition of miR-1236-3p upregulates Pim-3, p-Bad and Bcl-xL expression. To explore the molecular mechanism by which miR-1236-3p inhibition reduced neuronal apoptosis, the expressions of Pim-3, p-Bad, Bad and Bcl-xL, proteins associated with apoptosis, were analyzed via western blotting. Compared with the inhibitor control group, transfection with miR-1236-3p inhibitor significantly increased protein levels of Pim-3, p-Bad (Ser112) and Bcl-xL in neuronal cells (Fig. 6), which were in turn reversed by co-transfection with TPT1-siRNA (Fig. 6).

\section{Discussion}

In the present study, it was demonstrated that miR-1236-3p was upregulated in the hippocampus of newborn rats with $\mathrm{CH}$. TPT1 was a direct target of miR-1236-3p, which was revealed to be downregulated in the hippocampus of newborn rats with $\mathrm{CH}$. Inhibition of miR-1236-3p expression protected hippocampal neurons from apoptosis induced by $\mathrm{CH}$ in vivo. In addition, the present study also revealed that miR-1236-3p inhibition prevented neurons from apoptosis and upregulated Pim-3, p-Bad (Ser112) and Bcl-xL protein expression in vitro, all of which were reversed by TPT1 knockdown. 


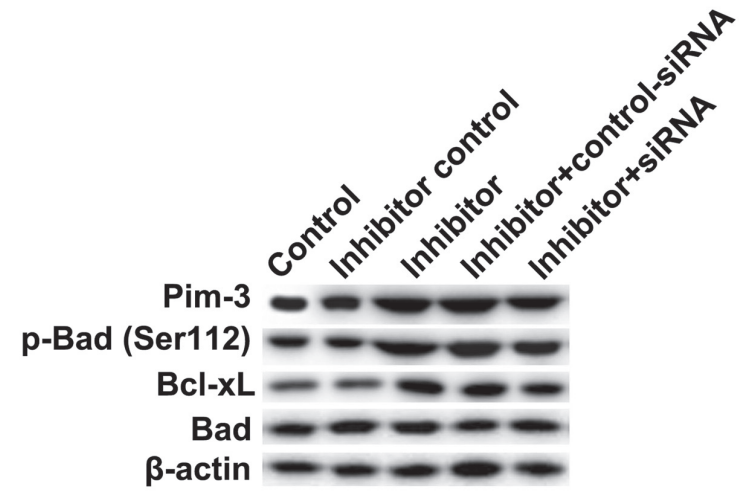

Figure 6. Effect of miR-1236-3p on the expression Pim-3, p-Bad and Bcl-xL in cultured neurons. The protein levels of Pim-3, p-Bad (Ser112), Bcl-xL in cultured neurons were detected via western blot analysis. miR, microRNA; p, phosphorylated; siRNA, small interfering RNA.

$\mathrm{CH}$ leads to decreased developmental quotient, mental retardation and increased depression/anxiety scores in patients (6,28-31). Clinical phenomenon (including short stature and mental retardation) suggested that thyroid hormone synthesis and secretion reduction leads to developmental delay and neurological deficits (32). In addition, TH deficiency can lead to hippocampal neuronal cell injury and cell apoptosis (33). miRNAs have been revealed to serve a critical role in diseases associated with the nervous system, including autoimmune neuroinflammation (34), Alzheimer's disease (35), Parkinson's disease (36) and $\mathrm{CH}$ (16). A previous study has reported that miR-124 can protect neurons from apoptosis in rat models of hypothyroidism (16). In the case of miR-1236, it has been reported to induce cell apoptosis in bladder cancer cells by inhibiting p21 expression (37). However, the expression and role of $\mathrm{miR}-1236-3 \mathrm{p}$ in $\mathrm{CH}$ remain unclear. In the present study, it was determined that miR-1236-3p was significantly upregulated in the hippocampal tissue of newborn rats with $\mathrm{CH}$, where TPT1 was identified as one of its direct targets. Supporting this notion, it was also identified that TPT1 was downregulated in the hippocampus tissues of newborn rats with $\mathrm{CH}$. TPT1 is a translationally controlled oncogene, where it was found to be upregulated in a variety of malignancies including glioma $(20)$, pancreatic $(21,22)$, breast (38) and colorectal cancer (39). It was also revealed to enhance tumor cell proliferation whilst inhibiting cell apoptosis. Hippocampal neuronal cell apoptosis is one of the main characteristics of $\mathrm{CH}(11,12,16)$. Therefore, the results from the present study suggested that miR-1236-3p may affect $\mathrm{CH}$ progression by regulating neuronal cell apoptosis by targeting TPT1. Subsequently, the effect of miR-1236-3p on hippocampal neuronal cell apoptosis in rats with $\mathrm{CH}$ was investigated. The results of the present study revealed that $\mathrm{CH}$ induction increased apoptosis of neurons in the hippocampus of rats, which was alleviated by the inhibition of miR-1236-3p expression in vivo. The in vitro results also indicated that miR-1236-3p inhibition enhanced neuronal cell viability and prevented apoptosis.

Pim-3 is a member of the proto-oncogene Pim family and is reported to regulate cell survival, proliferation and cell cycle in during tumor development (40). A previous study demonstrated that Pim-3 may inhibit cell apoptosis by upregulating the phosphorylation of Bad and the expression of the anti-apoptotic molecule Bcl-xL (41). In particular, TPT1 can interact with Pim-3 to enhance Pim-3 protein stability (22). A previous study has reported that miR-216b-5p regulates pancreatic cancer progression by regulating TPT1/Pim-3 signaling (42). miR-216b-5p upregulation suppressed Pim-3, p-Bad and Bcl-xL protein expression in pancreatic cancer cells, which was partly reversed by TPT1 upregulation (42). In the present study, the results revealed that the inhibition of miR-1236-3p significantly increased TPT1, Pim-3, p-Bad (Ser112) and Bcl-xL protein expression in hippocampal neurons. In addition, it was demonstrated that TPT1-siRNA transfection reversed the upregulation of Pim-3, p-Bad (Ser112) and Bcl-xL protein expression caused by miR-1236-3p inhibition. Therefore, miR-1236-3p could regulate neuronal cell apoptosis in the hippocampus in a $\mathrm{CH}$ rat model by regulating TPT1/Pim-3 signaling.

In conclusion, the present study indicated that miR-1236-3p was upregulated in new born rats with $\mathrm{CH}$. Inhibition of miR-1236-3p protected neurons from apoptosis by upregulating the TPT1/Pim-3 axis. These results indicated that miR-1236-3p may be a new potential therapeutic target for the treatment of $\mathrm{CH}$.

\section{Acknowledgements}

Not applicable.

Funding

No funding was received.

\section{Availability of data and materials}

The datasets used and/or analyzed during the current study are available from the corresponding author on reasonable request.

\section{Authors' contributions}

TM and SS contributed to study design, data collection, statistical analysis, data interpretation and manuscript preparation. CL and XL contributed to data collection and statistical analysis. All authors read and approved the final manuscript.

\section{Ethics approval and consent to participate}

All animal care and experimental procedures were performed in accordance with the National Institutes of Health Guide for Care and approved by the Animal Ethics Committee of the First Hospital of Jilin University.

\section{Patient consent for publication}

Not applicable.

\section{Competing interests}

The authors declare that they have no competing interests. 


\section{References}

1. Pardo Campos ML, Musso M, Keselman A, Gruñeiro L, Bergadá I and Chiesa A: Cognitive profiles of patients with early detected and treated congenital hypothyroidism. Arch Argent Pediatr 115: 12-17, 2017

2. Knowles RL, Oerton J, Cheetham T, Butler G, Cavanagh C, Tetlow $L$ and Dezateux C: Newborn screening for primary congenital hypothyroidism: Estimating test performance at different TSH thresholds. J Clin Endocrinol Metab 103: 3720-3728, 2018.

3. LaFranchi S: Congenital hypothyroidism: Etiologies, diagnosis, and management. Thyroid 9: 735-740, 1999.

4. Akaike M, Kato N, Ohno H and Kobayashi T: Hyperactivity and spatial maze learning impairment of adult rats with temporary neonatal hypothyroidism. Neurotoxicol Teratol 13: 317-322, 1991

5. Hashimoto K, Curty FH, Borges PP, Lee CE, Abel ED, Elmquist JK, Cohen RN and Wondisford FE: An unliganded thyroid hormone receptor causes severe neurological dysfunction. Proc Natl Acad Sci USA 98: 3998-4003, 2001.

6. Shimokawa N, Yousefi B, Morioka S, Yamaguchi S, Ohsawa A, Hayashi H, Azuma A, Mizuno H, Kasagi M, Masuda H, et al: Altered cerebellum development and dopamine distribution in a rat genetic model with congenital hypothyroidism J Neuroendocrinol 26: 164-175, 2014

7. Porterfield SP and Hendrich CE: The role of thyroid hormones in prenatal and neonatal neurological development-current perspectives. Endocr Rev 14: 94-106, 1993.

8. Mendes-de-Aguiar CB, Alchini R, Zucco JK, Costa-Silva B, Decker H, Alvarez-Silva M, Tasca CI and Trentin AG: Impaired astrocytic extracellular matrix distribution under congenital hypothyroidism affects neuronal development in vitro. J Neurosc Res 88: 3350-3360, 2010.

9. Koibuchi N: The role of thyroid hormone on cerebellar development. Cerebellum 7: 530-533, 2008

10. Koibuchi N: Animal models to study thyroid hormone action in cerebellum. Cerebellum 8: 89-97, 2009.

11. Zendel BR, Willoughby KA and Rovet JF: Neuroplastic effects of music lessons on hippocampal volume in children with congenital hypothyroidism. Neuroreport 24: 947-950, 2013.

12. Huang XW, Yin HM, Ji C, Qin YF, Yang RW and Zhao ZY: Effects of perinatal hypothyroidism on rat behavior and its relation with apoptosis of hippocampus neurons. J Endocrinol Invest 31: 8-15, 2008 .

13. Bongers-Schokking JJ and de Muinck Keizer-Schrama SM Influence of timing and dose of thyroid hormone replacement on mental, psychomotor, and behavioral development in children with congenital hypothyroidism. J Pediatr 147: 768-774, 2005.

14. Zaravinos A: The regulatory role of MicroRNAs in EMT and cancer. J Oncol 2015: 865816, 2015.

15. Shukla GC, Singh J and Barik S: MicroRNAs: Processing, maturation, target recognition and regulatory functions. Mol Cell Pharmacol 3: 83-92, 2011

16. Li W, Song D, Sun Y, Lv Y and Lv J: microRNA-124-3p inhibits the progression of congenital hypothyroidism via targeting programmed cell death protein 6. Exp Ther Med 15: 5001-5006, 2018.

17. Jones D, Li Y, He Y, Xu Z, Chen $\mathrm{H}$ and Min W: Mirtron microRNA-1236 inhibits VEGFR-3 signaling during inflammatory lymphangiogenesis. Arterioscler Thromb Vasc Biol 32: 633-642, 2012

18. Wang Y, Yan S, Liu X, Zhang W, Li Y, Dong R, Zhang Q, Yang Q Yuan C, Shen K and Kong B: miR-1236-3p represses the cell migration and invasion abilities by targeting ZEB1 in high-grade serous ovarian carcinoma. Oncol Rep 31: 1905-1910, 2014

19. Chan TH, Chen L and Guan XY: Role of translationally controlled tumor protein in cancer progression. Biochem Res Int 2012: 369-384, 2012

20. Gu X, Yao L, Ma G, Cui L, Li Y, Liang W, Zhao B and Li K: TCTP promotes glioma cell proliferation in vitro and in vivo via enhanced $\beta$-catenin/TCF-4 transcription. Neuro Oncol 16: 217-227, 2014.

21. Kaarbo M, Storm ML, Qu S, Wæhre H, Risberg B, Danielsen HE and Saatcioglu F: TCTP is an androgen-regulated gene implicated in prostate cancer. PLoS One 8: e69398, 2013.

22. Zhang F, Liu B, Wang Z, Yu XJ, Ni QX, Yang WT, Mukaida N and Li YY: A novel regulatory mechanism of Pim-3 kinase stability and its involvement in pancreatic cancer progression. Mol Cancer Res 11: 1508-1520, 2013.

23. Zhang L, Wang Q, Wang F, Zhang X, Zhang L, Tang Y and Wang S: LncRNA LINC01446 promotes glioblastoma progression by modulating miR-489-3p/TPT1 axis. Biochem Biophys Res Commun 503: 1484-1490, 2018.
24. Fabian ID, Rosner M, Fabian I, Vishnevskia-Dai V, Zloto O, Shinderman Maman E, Cohen K, Ellis M, Lin HY, Hercbergs A, et al: Low thyroid hormone levels improve survival in murine model for ocular melanoma. Oncotarget 6 : 11038-11046, 2015 .

25. Xu LJ, Ouyang YB, Xiong X, Stary CM and Giffard RG Post-stroke treatment with miR-181 antagomir reduces injury and improves long-term behavioral recovery in mice after focal cerebral ischemia. Exp Neurol 264: 1-7, 2015.

26. Huang YN, Lai CC, Chiu CT, Lin JJ and Wang JY: L-ascorbate attenuates the endotoxin-induced production of inflammatory mediators by inhibiting MAPK activation and NF- $\mathrm{kB}$ translocation in cortical neurons/glia Cocultures. PLoS One 9: e97276, 2014.

27. Livak KJ and Schmittgen TD: Analysis of relative gene expression data using real-time quantitative PCR and the 2(-Delta Delta C(T)) method. Methods 25: 402-408, 2001.

28. Wang S, Teng W, Gao Y, Fan C, Zhang H and Shan Z: Early levothyroxine treatment on maternal subclinical hypothyroidism improves spatial learning of offspring in rats. J Neuroendocrinol 24: 841-848, 2012.

29. Sartim AG, Brito BM, Gobira PH and Joca SRL: Attenuation of glutamatergic and nitrergic system contributes to the antidepressant-like effect induced by capsazepine in the forced swimming test. Behav Pharmacol 30: 59-66, 2019.

30. Berbel P, Mestre JL, Santamaria A, Palazón I, Franco A, Graells M, González-Torga A and de Escobar GM: Delayed neurobehavioral development in children born to pregnant women with mild hypothyroxinemia during the first month of gestation: The importance of early iodine supplementation. Thyroid 19: 511-519, 2009.

31. Velasco I, Carreira M, Santiago P, Muela JA, García-Fuentes E, Sánchez-Muñoz B, Garriga MJ, González-Fernández MC, Rodríguez A, Caballero FF, et al: Effect of iodine prophylaxis during pregnancy on neurocognitive development of children during the first two years of life. J Clin Endocrinol Metab 94: 3234-3241, 2009.

32. Mastorakos G, Karoutsou EI, Mizamtsidi M and Creatsas G: The menace of endocrine disruptors on thyroid hormone physiology and their impact on intrauterine development. Endocrine 31: 219-237, 2007

33. Guo Y, Wan SY, Zhong X, Zhong MK and Pan TR: Levothyroxine replacement therapy with vitamin E supplementation prevents the oxidative stress and apoptosis in hippocampus of hypothyroid rats. Neuro Endocrinol Lett 35: 684-690, 2014.

34. Ghorbani S, Talebi F, Chan WF, Masoumi F, Vojgani M, Power C and Noorbakhsh F: MicroRNA-181 variants regulate T cell phenotype in the context of autoimmune neuroinflammation. Front Immunol 8: 758, 2017.

35. Song $\mathbf{J}$ and Kim YK: Identification of the role of miR-142-5p in Alzheimer's disease by comparative bioinformatics and cellular analysis. Front Mol Neurosci 10: 227, 2017.

36. Grasso M, Piscopo P, Confaloni A and Denti MA: Circulating miRNAs as biomarkers for neurodegenerative disorders. Molecules 19: 6891-6910, 2014.

37. Wang C, Chen Z, Ge Q, Hu J, Li F, Hu J, Xu H, Ye Z and Li LC: Up-regulation of p21(WAF1/CIP1) by miRNAs and its implications in bladder cancer cells. FEBS Lett 588: 4654-4664, 2014

38. Neuhäuser K, Küper L, Christiansen H and Bogdanova N: Assessment of the role of translationally controlled tumor protein 1 (TPT1/TCTP) in breast cancersusceptibility and ATM signaling. Clin Transl Radiat Oncol 15: 99-107, 2019.

39. Li R, Zhu H, Yang D, Xia J and Zheng Z: Long noncoding RNA lncBRM promotes proliferation and invasion of colorectal cancer by sponging miR-204-3p and upregulating TPT1. Biochem Biophys Res Commun 508: 1259-1263, 2019.

40. Mukaida N, Wang YY and Li YY: Roles of Pim-3, a novel survival kinase, in tumorigenesis. Cancer Sci 102: 1437-1442, 2011.

41. Li YY, Popivanova BK, Nagai Y, Ishikura H, Fujii C and Mukaida N: Pim-3, a proto-oncogene with serine/threonine kinase activity, is aberrantly expressed in human pancreatic cancer and phosphorylates bad to block bad-mediated apoptosis in human pancreatic cancer cell lines. Cancer Res 66: 6741-6747, 2006.

42. You Y, Tan J, Gong Y, Dai H, Chen H, Xu X, Yang A, Zhang Y and Bie P: MicroRNA-216b-5p Functions as a Tumor-suppressive RNA by targeting TPT1 in pancreatic cancer cells. J Cancer 8: 2854-2865, 2017

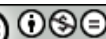

This work is licensed under a Creative Commons Attribution-NonCommercial-NoDerivatives 4.0 International (CC BY-NC-ND 4.0) License. 